\title{
Research on a Special Processing Method of Paraffin Carving
}

\author{
Zheng-hong Zhu \\ Hefei university of technology \\ zh_zhu@sohu.com
}

\author{
YangZhang \\ Hefei university of technology \\ Zhangyang163.2008@163.com
}

\begin{abstract}
The special processing method of paraffin was introduced, which was processed by a special cutting tool- Hot-Knife. This paper adopted this method for processing paraffin, proposed the implementation requirements for conditions of paraffin, structure of the cutting tool and working principle of the machine, as well as discussed a variety of factors affecting the processing speed of this tool. In addition, feasible design results were worked out through the orthogonal test.
\end{abstract}

Keywords-Special Processing; Hot-knife; Orthogonal test; Paraffin

\section{INTRODUCTION}

In recent years, with the development of sculpture technology, special processing materials used in sculpture technology have become a trend. The paraffin product as raw material have already been used in a wide range, while carving technique of paraffin material also have a very good market prospects. Paraffin is apt to stick to the knife and paraffin chips are difficult to remove when cutting, so traditional processing methods are difficult to meet the need of precision and accuracy of paraffin products. Paraffin is soft, solid at normal room temperature and changes into liquid or gaseous when temperature rises. How to make use of these physical characteristics of paraffin and design a cutting machine is the basic idea of this article.

Currently, scan technology and equipment through photographing or scanning statue to get an outline three dimensional coordinates has become more and more mature. But there are no suitable machine tools for using this data to process statue. Although the existing centres and multi-axis machines have 5 degree of freedom and tilt of the tool, but do not have a cantilevered body, cannot be processed within the concave surfaces and complex profiles. Moreover, they cannot be clamped by milling cutters with diameter less than $3 \mathrm{~mm}$ and their processing of small objects are clearly inadequate and delicate. Machine tools of this class mainly process hard metals, which require a high level of rigidity and cutting force on the machine itself. Complex structure and high cost also make these machine tools inapplicable in statue field. In addition, although three dimensional carving machine on the market costs lower than machining center, but is still equipped with spinning milling cutter, not inclined to pitch, and cannot process hole or groove that is no upright on the datum plane, thus it cannot satisfy the need of carved molding.
This article chiefly designs and researches the cutter of paraffin and the processing principle of carving, and discusses the factors that affect the processing efficiency, in order to lay the foundation for more in-depth study in this field in the future.

\section{SELECTIVE REQUIREMENTS FOR PARAFFIN}

Paraffin came mainly from oil refining in China, which has wilder melting range, the larger kinematic viscosity, smaller solid hardness at room temperature and so on. So it would be inappropriate to be processed. The paraffin should be required as following characteristics in the processing methods which used in this article.

\section{A. The narrower range of melting point of paraffin}

Its melting point cannot be too high and should not exceed $5^{\circ} \mathrm{C}$ temperature difference between upper and lower bounds, the smaller the better. The narrower range of melting point of the paraffin wax, the easier to control melt temperature of processing paraffin. Thus it is helpful for controlling the temperature of the machine tool.

B. A certain degree of hardness be required in solid paraffin at normal temperature

Solid paraffin should have sufficient hardness at room temperature and penetration should be no more than 20 (25 ${ }^{\circ} \mathrm{C}, 1 / 10 \mathrm{~mm}$ ), the harder the better, which is in favor of clamping and fixing of paraffin. Therefore, the small deformation of the paraffin reduces the deformation in the process.

\section{Smaller kinematic viscosity}

When machining paraffin, paraffin kinematic viscosity has a very important significance. The larger kinematic viscosity, the easier sticking knife when processing paraffin, and the harder separate removal of paraffin from processing surface, therefore it can't guarantee the quality of machined surface. Kinematic viscosity should be as small as possible, and not more than $20 \mathrm{~mm}^{2} / \mathrm{s}$ at $100^{\circ} \mathrm{C}$.

\section{Melting point should not be too high}

Due to ambient temperature requirements of controlling paraffin cutting close to the melting point of wax, while cutting also have hot, if the wax melting point is too high, it is more difficult to select this power vacuum pump for high temperature environment. So it is required that the melting 
point should be between $50 \sim 70^{\circ} \mathrm{C}$, lower is better.

The paraffin which meets the above requirements can be used for processing. Statistics show ${ }^{[2]}$ that paraffin is mixed with stearic acid by 1:1 can meet the above requirements. This mixed paraffin, not only can be repeatedly recycled and has low cost, but also has a certain degree of ductility and hardness. In addition, the rubber protective wax and foundry mold wax can be used for processing.

\section{Structure OF THE Hot-KNIFE AND WORKING PRINCIPLE OF CARVING}

\section{A. Structure of the Hot-Knife}

Hot-Knife is a cutting tool for machining paraffin, which is a new type of cutting tool which can quickly remove the material at an appropriate controlled temperature. Because of different formulations of paraffin, whose melting point is different, controlled temperature of Hot-Knife is also different. Its structure is in Figure 1 as follows:

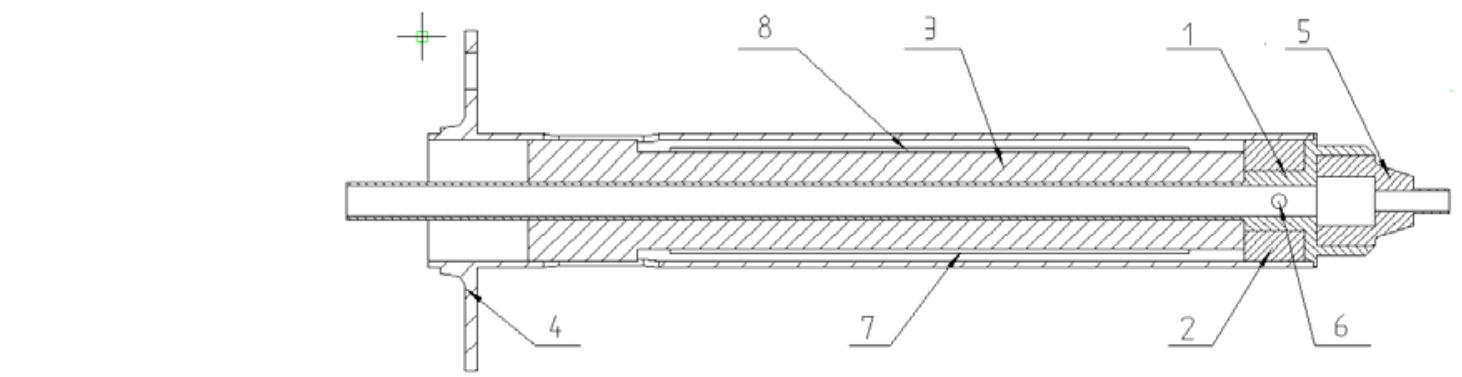

1-Heart center, 2-Heart connection, 3-Inside the external wrapping rubber sleeve, 4-outer sleeve, 5-Nozzle, 6-Connecting thread holes, 7-Temperature sensor, 8-Heating core

Figure 1 Hot-Knife

Hot-Knife, is mainly composed of the inner core, outer consists of sensors and nozzle. Inside of the hot knife, it has a core electric heating (8) whose current is controlled by special workstations. The front of the Hot-Knife is small, making carving enough fine. In order to allow air flow which wrapped in melting scrap wax to go through the center of Hot-Knife, it is designed to be hollow. In order to accurately measure the temperature of hot knife cutter, temperature sensor (7) is preset in the center of the Hot-knife. Inner-core connector (2) is drilled with threaded holes (6), and connected with inner core and outer sleeve (4) through a screw. Heating wire is wrapped around the inner core of the external wound silk rubber tube (3), and covered by the outside cylinder.

\section{B. The Working Principle of Carving}

The working principle of carving as shown in figure 2.when the Hot-Knife was working, heating wire above the Heating wire wound rubber sleeve (5) was powered on for heating, and temperature along knife body conduction to head that let knife head of temperature quickly rise. When the temperature of the head of the Hot-Knife up to melting point value of the paraffin, temperature sensor (12) began to control the temperature which was constantly maintained in this a melting point for processing paraffin in suitable temperature. Paraffin block, which was quickly melted into melting state, came into contact with certain temperature of nozzle (2).During the course of exhaust by waste wax filling blowholes, the negative pressure was produced in waste wax tank (8), which produced much suction in the nozzle of the Hot-Knife. Therefore molten wax was absorbed through wax absorption piping by nozzle (3) to waste wax tank (8) and the material was removed. In the course of molten wax sucked by wax absorption piping by nozzle (3), as the temperature rose from nozzle (2) to electric silk, most of wax became wax really; and as the temperature declined from electric silk to waste wax tank suction waxes imports (9), so most of the wax really became wax which flowed down along the waxes imports and collected into the waste wax tank. When the paraffin stockpiled in the waste wax tank was full, you could remove it. It was one of the methods that the paraffin wax was heated and let the paraffin wax melt change into wax water for pouring out from the tank. It is able to reuse.

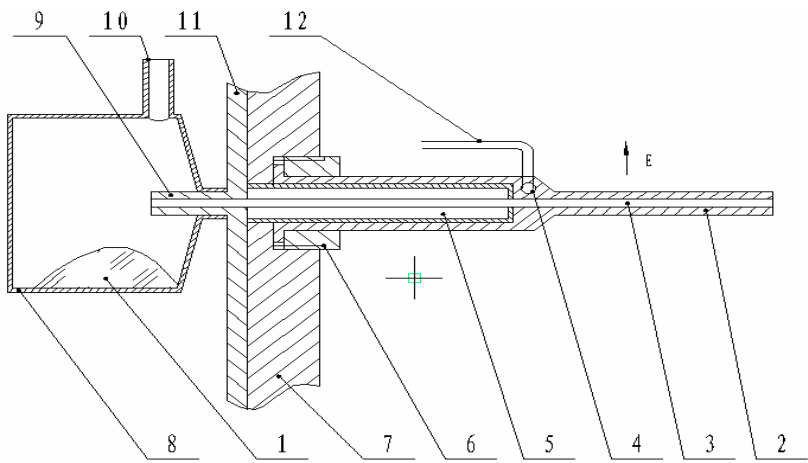

1- Paraffin wax, 2-Nozzle, 3-Wax absorption piping by Nozzle, 4 - Contact point temperature sensor, 5-Heating wire wound rubber sleeve, 6-Install the hot knife rubber sleeve, 7-Hot-Knife mounting plate, 8-Waste wax tank, 9-Waste wax tank suction waxes imports, 10-Waste wax filling blowholes , 11-Connect with seal soft tissue, 12-Temperature sensor

Figure 2 Principle diagram of Hot-knife

From the processing works, the size of the suction was affected by the air tightness of Hot-knife lumen, so the pressuretightnesss of Hot- Knife should be strictly ensured, particularly in the import and export of waste wax tank connections. If necessary, it can be coated with sealed glass glue. The temperature control device must be contained for controlling the temperature and ensure stability of temperature in order to suit industry different melting point of paraffin. 


\section{ANALYSIS OF FACTORS AFFECTING THE EFFICIENCY OF HOT-KNIFE PARAFFIN}

The campaign methods of Hot-knife were similar to common NC machining, which also contained roughing, semi-finishing and finishing. Because of a wax mold of broad outlines was formed in roughing, most of the wax had been removed in the process, so time cost most. Therefore, in order to ensure higher quality and quicker efficiency, this article mainly analysised the related factors of efficiency in roughing for the best process parameters.

There were several main factors affecting efficiency of paraffin in roughing. One was the suction power. The vacuum was used for gettering materials in processing, which should have enough suction. Second, it was the material removal rate. The removal wax is the space integration of cutting depth, cutting speed, feeding data of Hot-Knife. These three factors directly affect the overall effectiveness of the processing. Third one was cutter head diameter of hot-knife. When the diameter of the Hot-Knife segment was bigger, paraffin could be sucked faster, thus it could improve the speed; but the diameter should not be too big, because the allowance that rough processing leaved would create difficulties for subsequent processing. In addition the processing also could be influenced by the temperature of environment and segment.
With this special processing method for wax, there was the smaller torque and cutting force in hot-knife processing, and movement speed could be increased. In order to increase processing speed, the factors that affect the cutting speed were set about for experimental analysis.

\section{A. experimental condition}

Cutter diameter was set at $3 \mathrm{~mm}$, the hot-Cutter's output voltage by thermostat was $115 \mathrm{~V}$, and ambient temperature $41^{\circ}$, and Pump parameters: Limiting negative pressure values $\geq 0.075 \mathrm{MPa}$, pumping rate $\geq 15 \mathrm{~L} / \mathrm{min}$. Normal paraffin wax and stearic acid mixed by 1:1 were proposed in the paper, head intact.

\section{B. Experimental Programme}

Based on the analysis of the factors which influenced paraffin processing, reducing the roughing time consuming was the main purpose of the experiment. As the cutting depth (Depth of cut in $Z$ direction), the feeding data (Mobile space in $\mathrm{Y}$ direction) and the cutting speed (Cutting speed in $\mathrm{X}$ direction) were the most significant factors in this cut motion, $3 \times 3$ orthogonal analysis could be used for those important factors in the effect of processing speed. (This article the direction of $\mathrm{X} / \mathrm{Y} / \mathrm{Z}$ is the same as standard horizontal milling machine)

\section{Experimental Results}

TABLE 1

\begin{tabular}{|c|c|c|c|}
\hline $\begin{array}{c}\text { Depth of } \\
\text { cutting in } \\
\text { direction }\end{array}$ & $\begin{array}{c}\text { Mobile space } \\
\text { in Y direction }\end{array}$ & $\begin{array}{c}\text { The percentage of speed }(1000 \mathrm{~mm} / \mathrm{min}) \text { when } \\
\text { cutting paraffin wax totally sucked or not see } \\
\text { white forth of foam in X direction }\end{array}$ & $\begin{array}{c}\text { The percentage of speed } \\
\text { (1000mmin) when cutting } \\
\text { extruded paraffin not be all sucked } \\
\text { in X direction }\end{array}$ \\
\hline \multirow{3}{*}{1} & 0.75 & $50 \%$ & $80 \%$ \\
\cline { 2 - 4 } & 1.5 & $50 \%$ & $65 \%$ \\
\cline { 2 - 4 } & 2.25 & $20 \%$ & $40 \%$ \\
\cline { 2 - 4 } & 0.75 & $30 \%$ & $20 \%$ \\
\cline { 2 - 4 } & 1.5 & $10 \%$ & $12 \%$ \\
\hline \multirow{3}{*}{3} & 2.25 & $8 \%$ & $30 \%$ \\
\cline { 2 - 4 } & 0.75 & $15 \%$ & $10 \%$ \\
\hline
\end{tabular}

During the manufacturing process, feed rate should be above $30 \% \times 1000 \mathrm{~mm} / \mathrm{min}$.

\section{Interpretation of result}

- When the mobile space became larger in Y direction, feed rate should not be too high. At this point, most of the nozzle plane of the knife was blocked and the wax was merely absorbed by a small portion.

- when the mobile space In Y direction reached three-fourths of the cutter diameter, feed rate was very low and most waxes were extruded, not being sucked away.

- The sufficient diameter of knives should be insured and the mobile space in $\mathrm{Y}$ direction cannot exceed one-second of the cutter diameter.

- The smaller cutting in $Z$ direction, which is $1 \mathrm{~mm}$, Knife speed quickly and its feed rate can be up to $1000 \times 80 \% \mathrm{~mm} /$ minute. Observation, if the knife speed became much faster, the wax powders were extruded.
- If Cutting depth increased in $\mathrm{Z}$, feed rate reduced and the more wax was cut per unit of time. Thus wax sucked harder.

- The cutting depth was best not to exceed $3 \mathrm{~mm}$ in $\mathrm{Z}$ direction which caused slower feed rate.

- In the case of guaranteeing processing efficiency, $z$ depth cannot exceed $2 \mathrm{~mm}$ when processing.

\section{CONCLUSIONS}

Under the appropriate conditions of the selection of paraffin, it should be ensured that pump had enough suction power and Paraffin removal system had good air tightness. Meanwhile, if the conditions of the environmental temperature of paraffin processing and the cutter-head temperature of hot-knife processing were well controlled, the above experimental results showed that the processing effect of paraffin was directly associated with the cutting element. It was also shown that this special method of processing paraffin 
guaranteed paraffin a good surface quality and molding precision. During the procession, it required the depth of cutting in $\mathrm{Z}$ direction should not exceed $3 \mathrm{~mm}$ and the mobile space in $\mathrm{Y}$ direction should not exceed half of the cutter diameter, at the same time should improve cutting speed as much as possible in order to ensure the wax was completely sucked.

\section{REFERENCES}

[1] wei he; bin liu; liang zhang; The development and application of NC milling machining materials based on Paraffin and Stearic acid 【J】 2007-03

[2] yuye yan; Effects of additives on physical properties of paraffin wax【 J】 $2007-06$

[3] gang xing; The hot-knife of the cutter head quickly replaced in wax carving machines【P】2011-03

[4] houjiang zhang; yue qian; jing zhao; Wood laser engraving technology research【J】2006,34(2)

[5] zhongan xu; tianbao wang; changying li; liyan bao; qinmei ma; yuning miao; Introduction to orthogonal experimental design method 【J】 $2002,12(5)$ 